\title{
ОПЕРАЦИОННОЕ УПРАВЛЕНИЕ В ОБОРОННО-ПРОМЫШЛЕННОМ КОМПЛЕКСЕ
}

\author{
Е. А. Калинин \\ Московский гуманитарный университет
}

Аннотация: В статье дано определение оборонно-промышленного комплекса, описаны особенности операционного управления в ОПК, причины длительного сохранения этого подхода, а так же основные недостатки присущие ему в ОПК.

Ключевые слова: оборонно-промышленный комплекс; государственная безопасность; операционное управление; бизнес-процесс; организация

\section{OPERATIONAL MANAGEMENT IN THE MILITARY-INDUSTRIAL COMPLEX}

\author{
E. A. Kalinin \\ Moscow University for the Humanities
}

Abstract: This article provides a definition of the military-industrial complex, descriptions of the features of operational management in MIC, the reasons for the longterm preservation of this approach, as well as its main drawbacks in MIC.

Keywords: military-industrial complex; state security; operational management; business process; organization

В современных российских экономических словарях определение оборонно-промышленного комплекса (ОПК) не встречается. Поэтому перед описанием подходов к управлению необходимо дать его определение.

В. А. Цветков определяет ОПК как совокупность научно-исследовательских, испытательных организаций и промышленных предприятий, выполняющих разработку, производство, хранение, постановку на вооружение военной и специальной техники, амуниции, боеприпасов и т. п. преимущественно для государственных силовых структур, а также на экспорт (Цветков, 2015: Электр. ресурс).

На практике определение ОПК исходит из законодательного закрепления определенных предприятий, однако критерии, на основании которых производится их выбор, часто неизвестны. Так в Федеральном законе № 57ФЗ от 29 апреля 2008 года есть следующее определение ОПК: «хозяйственное общество, имеющее стратегическое значение для обеспечения оборо- 
ны страны и безопасности государства» (Федеральный закон ... , 2008: 10).

На основании приведенных выше определений, по мнению автора, целесообразно дать следующее определение ОПК.

ОПК - совокупность обществ с любой формой организации, чья деятельность в первую очередь связана с выполнением государственных оборонных заказов (ГО3), имеющих стратегическое значение для обеспечения обороны страны и безопасности государства.

При этом под безопасностью государства необходимо понимать не только военную безопасность, но также экономическую, научную и технологическую.

Таким образом, можно определить значение данного понятие для ОПК.

Государственная безопасность - это совокупность военной, технологической, научной и социальной защищенности государства от негативного воздействия из вне, а также возможность обеспечения устойчивого экономического роста, роста человеческого капитала и благосостояния общества в целом.

Как правило, в рамках ГОЗ осуществляется производство военной техники и техники двойного назначения в интересах государства или развитие научного и технологического потенциала государства, ведущего к повышению оборонной способности государства, что имеет стратегическое значение для обеспечения безопасности и устойчивого развития государства.

Так же неотъемлемой составляющей безопасности государства являются работы над изделиями военной техники и техники двойного назначения в интересах иностранного заказчика.

Одной из главных характеристик любого общества ведущего хозяйственную деятельность является система управления, реализованная в данном обществе.

Несмотря на то, что ОПК должен являться основным драйвером научных, технологических и экономических подходов, в настоящее время в ОПК РФ господствующим подходом управления является операционный. Длительность сохранения данного подхода в отрасли в первую очередь обусловлена:

- высокой закрытостью сектора ОПК от инноваций международного рыночного сектора в течение формирования комплекса как отдельного сектора экономики;

- общим отставанием развития подходов к управлению в отечественном гражданском секторе;

- отсутствием современного сформированного представления о подходах к управлению, основанных на национальных особенностях;

- чувствительностью к изменению структуры и принципов управления; 
Научные труды Московского гуманитарного университета 2018 № 5

- высокой технологичностью производств;

- высокой продолжительностью обязательств;

- плановой системой финансирования в рамках ГОЗ слабо отличающейся от системы, использовавшейся в СССР.

Кроме того, одной из причин сохранения операционного подхода к управлению является сам взгляд на общества, из которых состоит ОПК. Исходя из экономической и законодательной практики можно определить, что под обществами в ОПК имеется ввиду не что иное, как организации, за исключением того, когда в контексте под обществом подразумеваются концерны, то есть крупнейшие объединения организаций.

В общем смысле организация - группа людей, деятельность которых сознательно координируется с целью достижения общих целей. Однако общее представление не позволяет раскрыть сущность организации в ОПК. Таким образом, с точки зрения автора, необходимо несколько скорректировать это понятие.

Организация в ОПК - группа людей, деятельность которых сознательно координируется с целью обеспечения государственной безопасности.

От части именно эта особенность организации в ОПК является еще одной из причин длительного сохранения операционного управления в отрасли. В рыночном подходе в секторе ОПК основной целью деятельности организации является извлечение прибыли и получение стратегической доли сектора рынка. Рыночные механизмы конкуренции и необходимость обеспечения высокой эффективности деятельности при разработках инновационных технологий в ракетно-космической области обусловили совершенствование механизмов управления с целью формирования новых подходов. Плановое управление ОПК в советские годы привело к совершенствованию планирования операций. В итоге в ОПК была создана эффективная система планирования, позволяющая массово производить военную технику, а также часть гражданской с возможностью быстрого перепрофилирования. Однако инновационная деятельность в области менеджмента и производства гражданской продукции была сильно ограничена плановой экономикой, от чего и не становилась очевидной острая необходимость в совершенствовании управленческих подходов для обеспечения конкурентных преимуществ.

Все перечисленные выше причины так же усугубляются консервативностью военного представительства министерства обороны РФ (ВП МО РФ). Вовлеченность этих структур в деятельность организаций приводит к сохранению хорошо исследованного и понятного операционного подхода к управлению.

Операционный подход к управлению - подход к управлению закон- 
ченными действиями по преобразованию ресурсов и \или информации для создания конечной продукции предприятия.

Исходя из определения ОПК определение операционного подхода к управлению можно уточнить.

Операционный подход к управлению в ОПК - подход к управлению законченными действиями по преобразованию ресурсов и \или информации для выполнения Г03, имеющего стратегическое значение для обеспечения безопасности государства.

Конечным этапом операционного подхода можно рассматривать успешное завершение бизнес-процесса.

С точки зрения ОПК бизнес-процесс - совокупность взаимосвязанных мероприятий или работ, направленных на создание определенного продукта или услуги для обеспечения безопасности государства.

В общем случае модель операционного менеджмента строится на следующих принципах:

- Plants. Организации - производители продуктов и услуг;

- Parts. Продукты и услуги.

- Planed control systems. Система, выполняющая функции контроля и управления.

- Process. Проектирование бизнес-процессов.

- People. Подбор персонала, необходимого для выполнения операций, входящих в процессы (Моисеева, Стерлигова, 2014) .

Для определения путей достижения целей, которые являются основой любой организации, их формализуют через определение задач, выполнение которых напрямую ведет к достижению цели. Соответственно можно сформулировать иное понятие организации.

Организация в ОПК - группа людей, деятельность которых направлена на выработку, постановку и решение задач, а также обеспечения управляющих и исполнительных воздействий, приводящих к выполнению ГОЗ или инициативных разработок и увеличению оборонной способности государства.

В операционном управлении элементарной единицей является операция.

Операция - это минимальная единица работ, которую невозможно или бессмысленно детализировать на более мелкую.

В операционном управлении целью является успешное выполнение бизнес-процесса, который состоит из элементарных операций, соответственно процесс определяется следующим образом.

Процесс - совокупность взаимосвязанных действий, направленных на достижение определенных результатов. 
Научные труды Московского гуманитарного университета 2018 № 5

Исходя из понимания сущности организации, в ОПК сущность процесса формулируется немного иначе.

Процесс в ОПК - совокупность операций, направленных на выполнение ГОЗ или инициативных разработок для увеличения оборонной способности государства.

Однако в операционном управлении имеется существенный недостаток. Он заключается в том, что выполнение процесса может не привести к достижению поставленной задачи. Это можно сформулировать как дуализм операционного управления.

Несоответствие операционного управления - несоответствие процессов задачам, для решения которых они были разработаны.

Несоответствие проявляется в том, что процессы разрабатываются исходя из достижения при их завершении успешного выполнения задачи, однако совершенно необязательно, что процессы ведут к выполнению задачи, или к выполнению ее в полной мере. При этом результат выполнения процесса виден только в конце цепочки операций.

Данная проблема может встречаться при любом подходе к управлению, однако в операционном управлении не формируются список факторов и система их отслеживания для корректирования процессов с целью достижения задачи.

В гражданском секторе несоответствие операционного управления может не нести таких рисков и потерь как в ОПК, поскольку оборонный сектор в основной своей деятельности связан с крупными разработками с большим количеством соисполнителей и высокой сложностью задач.

Следовательно, определение несоответствий результатов процессов и ожиданий несут большую угрозу, поскольку срыв ГОЗ сопряжен с большими финансовыми и репутационными потерями.

На операционное управление также воздействуют другие факторы:

- стабильно высокие требования к качеству продукции;

- малое время на выполнение процессов;

- ограниченность ресурсной базы и в первую очередь человеческой, требуемой для создания сложной высоко технологичной продукции;

- большой бюрократический аппарат;

- отсутствие отлаженной эффективной системы документооборота;

- сложность определения длительности этапа разработки и конечного вида продукции.

Кроме того, главной особенностью ОПК отличающей его от гражданского производства является обязательное участие в разработке конечного потребителя и выполнение работ в рамках тактико-технических заданий (ТТЗ). ВП МО РФ всегда участвовало в разработке новой техники и тем са- 
мым обеспечивало отслеживание соответствие результатов процессов на соответствие ТТЗ. Однако данное отслеживание ведется через согласование целого пакета обязательных документов. Участие ВП МО РФ, необходимость оформления пакета документов, позволяющих анализировать результат процессов требованиям ТТЗ, и целый цикл обязательных испытаний продукции позволяют значительно сгладить негативные факторы несоответствия операционного управления.

Однако даже участие ВП МО РФ происходит на конечных стадиях, что не позволяет своевременно отследить возникновение несоответствия операционного управления. Это приводит к срывам сроков договорных обязательств в рамках Г03, что может повлечь значительные финансовые и репутационные издержки. Кроме срыва сроков возможно полное не выполнение требований ТТЗ, что может привести к уголовной и административной ответственности управленческого персонала организации, а также может нести экзистенциальные риски для любой организации.

Другим очень важным негативным фактором операционного управления свойственного ОПК является подход к определению ресурсов как неограниченных.

Бескрайная финансовая база - предположение о возможности финансирования собственных работ в неограниченном размере за счет сверх высоких затрат государства в рамках ГОЗ.

При разработке процессов в ОПК крайне редко учитывается ресурсная база, особенно человеческая, что пытаются компенсировать более высокой стоимостью работ. Однако разработка процессов без учета влияния времени работ на качество и связи этих факторов с различным родом ограничений и влиянием всех этих факторов на стоимость работ приводит к необоснованным оценкам стоимости работ, которые могут оказаться не только значительно завышенными, но и заниженными, что очень негативно влияет на финансовое состояние организации.

Бескрайний человеческий капитал - представление организаций в ОПК об неограниченности собственного человеческого капитала, способного решать и формулировать сверхсложные задачи в рамках ГОЗ.

Человеческий капитал на сегодняшний день является самой большой проблемой ОПК в виду законодательных ограничений по изменению структуры организации и высокому требованию для специалистов при значительно меньших по сравнению с частным сектором фондах заработной платы. Это сильно ограничивает возможность предприятий ОПК к инновационной деятельности и создает дополнительные ограничения для основной деятельности. Особенно сильно недостаток человеческого капитала сказывается на сроках выполняемых работ, что является принципиально 
важным фактором в ОПК.

Данные подходы к определению собственной ресурсной базы формируют еще один существенный недостаток операционного управления в ОПК.

Бескрайняя ресурсная база - ложное представление организации о своих финансовых ресурсах и человеческом капитале при определении сроков выполнения работ в рамках ГОЗ при заданными в соответствии с ТТЗ показателями.

Таким образом при возможности создания эффективной системы выполнения процессов, операционный менеджмент в современном ОПК, характеризующемся стабильно высоким ростом сложности работ, во многом характеризуется несоответствием операционного менеджмента и бескрайней ресурсной базой. Эти недостатки сказываются не только на эффективности деятельности организации, но и на результативности, поскольку в ОПК организация может влиять только на собственную ресурсную базу. Длительность работ и их качество жестко заданы договорами и ТТЗ соответственно, что значительно снижает возможности организации при выполнении обязательств.

\section{СПИСОК ЛИТЕРАТУРЫ}

Федеральный закон от 29 апреля 2008 г. № 57-Ф3 «0 порядке осуществления иностранных инвестиций в хозяйственные общества, имеющие стратегическое значение для обеспечения обороны страны и безопасности государства» (2008) // Российская газета. 7 мая. С. 10.

Моисеева, Н. К., Стерлигова, А. Н. (2014) Управление операционной средой организации. Учебник. М.: ИНФРА-М. 336 с.

Цветков, В. А. (2015) Пути повышения эффективности и устойчивости развития оборонно-промышленного комплекса [Электронный ресурс] // Сайт конференции «Экономический потенциал промышленности на службе оборонно-промышленного комплекса» URL: http://экономикаопк.рф/ moderator-sektsii-1-finansovaya-politika-na-predpriyatiyah-opk (дата обращения: 21.04.2018)

Дата поступления: 15.09.2018 2.

Калинин Евгений Александрович - магистрант направления обучения «Управление проектами» кафедры менеджмента Московского гуманитарного университета. Адрес: 11395, Россия, г. Москва, ул. Юности, д. 5. Тел: +7 (916) 171-75-65. Эл. адрес: kalinineugene@inbox.ru. Научный руководитель - доц. Н. Ю. Аббас.

Kalinin Evgeniy Aleksandrovich, Graduate Student, Department of Management, Moscow University for the Humanities. Postal address: 5, Yunosti 
St., Moscow, Russian Federation, 111395. Tel.: +7 (916) 171-75-65. E-mail: kalinineugene@inbox.ru Scientific Advisor -N. Yu. Abbas, Associate Professor

\section{Для цитирования:}

Калинин Е. А. Операционное управление в оборонно-промышленном комплексе [Электронный ресурс] // Научные труды Московского гуманитарного университета. 2018. № 5. URL: http://journals.mosgu.ru/trudy/article/ view/831 (дата обращения: дд.мм.гг.). DOI: 10.17805/trudy.2018.5.11 